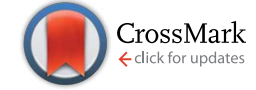

Cite this: J. Mater. Chem. A, 2016, 4, 5216

Received 18th February 2016

Accepted 9th March 2016

DOI: 10.1039/c6ta01472k

www.rsc.org/MaterialsA

\section{Maghemite nanoparticles decorated on carbon nanotubes as efficient electrocatalysts for the oxygen evolution reaction $\uparrow$}

\author{
Mohammad Tavakkoli, ${ }^{\text {*a }}$ Tanja Kallio, ${ }^{a}$ Olivier Reynaud, ${ }^{\text {b }}$ Albert G. Nasibulin, ${ }^{\text {bcd }}$ \\ Jani Sainio, ${ }^{b}$ Hua Jiang, ${ }^{\text {b }}$ Esko I. Kauppinen ${ }^{\mathrm{b}}$ and Kari Laasonen*a
}

\begin{abstract}
The oxygen evolution reaction (OER) is a critical reaction in electrochemical water splitting and rechargeable metal-air batteries to generate and store clean energy. Therefore, the development of efficient and low cost electrocatalysts for the OER with high activity and stability is of great technological and scientific interest. We demonstrate here for the first time that maghemite $\left(\gamma-\mathrm{Fe}_{2} \mathrm{O}_{3}\right)$ nanoparticles decorated on carbon nanotubes (CNTs) function as low cost, highly active and durable OER electrocatalysts. The material generates a current density of $10 \mathrm{~mA} \mathrm{~cm}{ }^{-2}$ at overpotentials of 0.38 and $0.34 \mathrm{~V}$ in 0.1 and $1 \mathrm{M} \mathrm{NaOH}$, respectively. These values are comparable to those of the best OER electrocatalysts reported so far. Moreover, $\gamma-\mathrm{Fe}_{2} \mathrm{O}_{3} / \mathrm{CNTs}$ show a stable performance at a potential of $\sim 1.64 \mathrm{~V}$ vs. RHE during $25 \mathrm{~h}$ stability tests. The $\gamma-\mathrm{Fe}_{2} \mathrm{O}_{3}$ nanoparticles are formed from carbon encapsulated iron nanoparticles (CEINs) during the first OER measurements of the CEIN/CNT electrode. The CEIN/CNT material itself is synthesized by a fast and low cost floating catalyst chemical vapor deposition method in a one-step synthesis with a similar growth process to that of CNTs.
\end{abstract}

\section{Introduction}

A promising method for the large-scale storage of intermittent energy from the sun, wind, and other renewable sources in the form of hydrogen $\left(\mathrm{H}_{2}\right)$ fuel is electrolytic water splitting in which hydrogen and oxygen gases are formed $\left(\mathrm{H}_{2} \mathrm{O} \rightarrow \mathrm{H}_{2}+\frac{1}{2} \mathrm{O}_{2}\right) \cdot{ }^{1-3} \mathrm{~A}$ critical step in the electrolysis of water is the oxygen evolution reaction (OER) which is kinetically sluggish since it involves four proton-coupled electron transfer steps and dioxygen bond formation $\left(4 \mathrm{OH}^{-} \rightarrow \mathrm{O}_{2}+2 \mathrm{H}_{2} \mathrm{O}+4 \mathrm{e}^{-}\right) .{ }^{4}$ The slow kinetics of the OER limits the efficiency of hydrogen production from water splitting. ${ }^{5}$ Thus, efficient catalyst materials are required to expedite the OER on the anode for generating hydrogen at the cathode with a favorable rate at relatively low applied voltages. For the OER, oxides of iridium $\left(\mathrm{IrO}_{2}\right)$ and ruthenium $\left(\mathrm{RuO}_{2}\right)$ are the active electrocatalysts with relatively low overpotentials and

${ }^{a}$ Department of Chemistry, Aalto University, School of Chemical Technology, P.O. Box 16100, FI-00076 Aalto, Finland. E-mail: mohammad.tavakkoli@aalto.fi; kari. laasonen@aalto.fi

${ }^{b}$ Department of Applied Physics, Aalto University, School of Science, P.O. Box 15100, FI 00076 Aalto, Finland

${ }^{c}$ St. Petersburg Polytechnic University, 195251, St. Petersburg, Russia

${ }^{d}$ Skolkovo Institute of Science and Technology, 143025, Skolkovo, Moscow Region, Russia

$\dagger$ Electronic supplementary information (ESI) available: Materials synthesis, electrochemical procedures, ECAS calculations, TEM images, Raman spectroscopy, XPS, RDE and RRDE measurements, CV curves, and supporting data. See DOI: $10.1039 / \mathrm{c} 6 \mathrm{ta} 01472 \mathrm{k}$
Tafel slopes. ${ }^{\mathbf{1}, \mathbf{6 - 8}}$ However, the high cost and scarcity of such noble metal based catalysts restrict their large-scale commercial applications. To replace these precious catalysts for the OER, the development of efficient catalysts based on the first-row transition metals such as $\mathrm{Ni}, \mathrm{Fe}, \mathrm{Co}$ and $\mathrm{Mn}$ has attracted increasing attention. ${ }^{4,8-19}$ Transition metal nanoparticles used as active catalysts are mostly decorated on conductive supports with highsurface area to facilitate charge transfer and to increase the number of active catalytic sites. Among such catalyst supports, carbon nanotubes (CNTs) are extremely attractive for heterogeneous electrocatalysis because of their unique structure and excellent electrical conductivity. ${ }^{20-22}$ Furthermore, CNTs have shown high stability for OER measurements in alkaline solutions $^{\mathbf{2 3 2 4}}$ making them interesting supports for OER catalysts. ${ }^{17,18,20,25}$

Recently, we presented a new strategy to synthesize metal nanoparticle/CNT hybrid materials in which both the catalyst particles and the CNT support are simultaneously synthesized by a novel one-step chemical vapor deposition (CVD) synthesis. $^{26}$ Here, we have used this fast and low cost CVD synthesis to grow carbon encapsulated iron nanoparticles (CEINs) decorated on CNTs (CEIN/CNT). In this study, we show that during the first potential sweeps for measuring the activity of this material for the OER, CEINs are altered to maghemite $\left(\gamma-\mathrm{Fe}_{2} \mathrm{O}_{3}\right)$ nanoparticles while the crystalline structure of CNTs is preserved. Then, the formed $\gamma-\mathrm{Fe}_{2} \mathrm{O}_{3} / \mathrm{CNT}$ material shows stable and high catalytic activity for the OER. It should be noted that the growth mechanism of the initial CEIN/CNT sample is 
similar to that of CNTs. However, the catalytic activity of this material is dramatically enhanced for the OER and comparable to the best electrocatalysts reported so far. Here, we also consider the change in the structure of carbon encapsulated metal nanoparticles, reported as highly active and durable catalyst materials, ${ }^{26-30}$ and CNTs during the OER electrochemical measurements.

\section{Results and discussion}

\subsection{Catalyst synthesis and characterization}

A one-step floating catalyst (aerosol) CVD synthesis was utilized to grow the CEIN/CNT material (see synthesis details in the ESI and Fig. S1 $\dagger$ ). This synthesis process has been recently used to produce highly conductive transparent films ${ }^{31}$ and active catalyst materials for the hydrogen evolution reaction. ${ }^{26}$ Shortly, an aerosolized feedstock solution of ferrocene $\left(\mathrm{C}_{10} \mathrm{H}_{10} \mathrm{Fe}\right)$ and thiophene $\left(\mathrm{C}_{4} \mathrm{H}_{4} \mathrm{~S}\right)$ in toluene $\left(\mathrm{C}_{7} \mathrm{H}_{8}\right)$ was introduced into a heated quartz tube. Ferrocene was decomposed to Fe nanoparticles at a high temperature. Toluene and ethylene $\left(\mathrm{C}_{2} \mathrm{H}_{4}\right)$ were the carbon sources for the CNT synthesis. The utilization of hydrocarbons results in a high reaction yield which is a key parameter for industrial applications. ${ }^{31}$ Fig. 1 shows transmission electron microscopy (TEM) images of the synthesized material in which we can see a mixture of CNTs and CEINs decorated on the CNTs. Iron nanoparticles used for the growth of CEINs and CNTs are shown in high-resolution TEM (HRTEM) images in Fig. $1 \mathrm{~b}$ and c, respectively.

After the decomposition of ferrocene, toluene and ethylene in the reactor, in the nucleation process of CNTs, graphene layers first appear around the metal clusters. Subsequently, the metal cluster assumes a conical shape and forms the characteristic protrusion, which expels a CNT and, then, elongates by the large forces exerted by the surrounding carbon tubes. In our sample, we observed (Fig. S2†) iron particles at different CNT growth steps from carbon-enclosed particles to particles with conical shapes and elongated particles surrounded by CNTs. The CEINs might be synthesized at the end of the hot zone of the reactor where they do not have enough time to form CNTs.

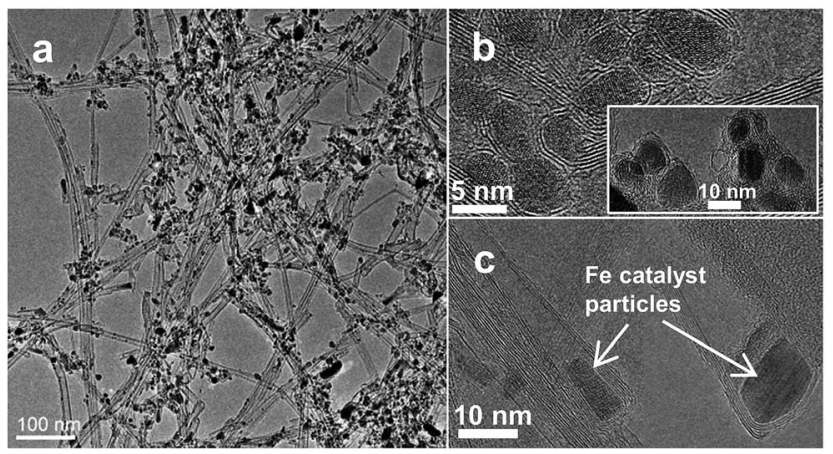

Fig. 1 Structure of the CEIN/CNT material. (a) TEM image of carbonencapsulated iron nanoparticles (CEINs) supported on CNTs showing the distribution of the particles on the CNTs; (b) HRTEM image of the CEINs; (c) HRTEM image of Fe catalyst particles for the growth of the CNTs.
This growth mechanism of CNTs and CEINs is suggested on the basis of earlier in situ observations for the growth of CNTs. ${ }^{32-34}$ The growth is highly dependent on the amount of iron source as, according to our earlier observations, the amount of CEINs will be decreased dramatically when the concentration of ferrocene is decreased. ${ }^{31}$ Size distribution analysis of Fe nanoparticles in CEINs (Fig. S3 $\dagger$ ) was performed from the HRTEM images of the CEIN/CNT sample and resulted in an average size of $5.4 \mathrm{~nm}$ for the carbon encapsulated metallic iron nanoparticles.

The catalytic activity of the CEIN/CNT catalyst for the OER was evaluated using a standard three-electrode electrochemical configuration in aqueous $\mathrm{NaOH}$ purged with $\mathrm{N}_{2}$ (see details of electrochemical procedures in the ESI $\dagger$ ). Fig. $\mathrm{S} 4 \dagger$ shows the first five OER sweeps for the CEIN/CNT sample in alkaline 0.1 and $1 \mathrm{M} \mathrm{NaOH}$ solutions, indicating that the current is almost stabilized after 3 anodic sweeps. The higher current in the first sweeps is attributed to the oxidation of carbon and iron. The following discussions show that during a few cycles in the OER potential region in an alkaline solution the CEIN/CNT material is converted to $\gamma-\mathrm{Fe}_{2} \mathrm{O}_{3} / \mathrm{CNTs}$. This material exhibits high and stable catalytic activity for the OER.

Fig. 2 displays TEM images taken from the CEIN/CNT material after the stabilization of the OER current in $0.1 \mathrm{M}$ $\mathrm{NaOH}$ by the continuous potential cycling between 1.0 and $1.65 \mathrm{~V}$ vs. reversible hydrogen electrode (RHE). Compared to Fig. 1 for the initial CEIN/CNT sample, it is visible that the graphene layers surrounding Fe nanoparticles in CEINs are diminished here. The TEM crystallographic investigations based on experimental and simulated electron diffraction ring patterns (Fig. 2e and f) clearly indicate that the uncovered nanoparticles are maghemite $\left(\gamma-\mathrm{Fe}_{2} \mathrm{O}_{3}\right)$. These results exhibit that the CEINs with pure Fe metallic cores have been transformed to $\gamma-\mathrm{Fe}_{2} \mathrm{O}_{3}$ nanoparticles after the potential cycling. Fig. $2 \mathrm{~g}$ indicates that although the graphite structure of the surface of the CNTs is preserved the hemispherical end-caps of the CNTs have also been opened by the continuous cycling in the alkaline solution. The presence of pentagonal rings and the great strain on the carbon atoms at the hemispherical tips of the CNTs and graphene layers surrounding the Fe particles in CEINs make them more reactive compared to the hexagonal structure of the sidewalls of the CNTs. ${ }^{35}$ This causes the caps of the CNTs and carbon cages around the Fe nanoparticles to selectively react with hydroxide $\left(\mathrm{OH}^{-}\right)$ions in the alkaline solution and thus they are stripped off. Subsequently, hydroxide ions react with the iron nanoparticles to form $\gamma-\mathrm{Fe}_{2} \mathrm{O}_{3}$ nanoparticles. Size distribution analysis of the $\gamma-\mathrm{Fe}_{2} \mathrm{O}_{3}$ nanoparticles (Fig. S5 $\dagger$ ) was performed from the HRTEM images of the $\gamma-\mathrm{Fe}_{2} \mathrm{O}_{3} / \mathrm{CNT}$ sample and resulted in an average size of $6.3 \mathrm{~nm}$ for the nanoparticles. The observed growth in the size of the nanoparticles is expected as oxygen is incorporated in the lattice of the metallic iron.

Raman spectroscopy of the CEIN/CNT and the $\gamma-\mathrm{Fe}_{2} \mathrm{O}_{3} / \mathrm{CNT}$ samples (Fig. S6 $\dagger$ ) revealed an increase of the relative amount of disordered carbon atoms as the ratio of $\mathrm{D}$ and $\mathrm{G}$ band intensities $\left(I_{\mathrm{D}} / I_{\mathrm{G}}\right)$ increased from 0.37 in the initial CEIN/CNT sample to 0.88 after current stabilization upon the above-mentioned 


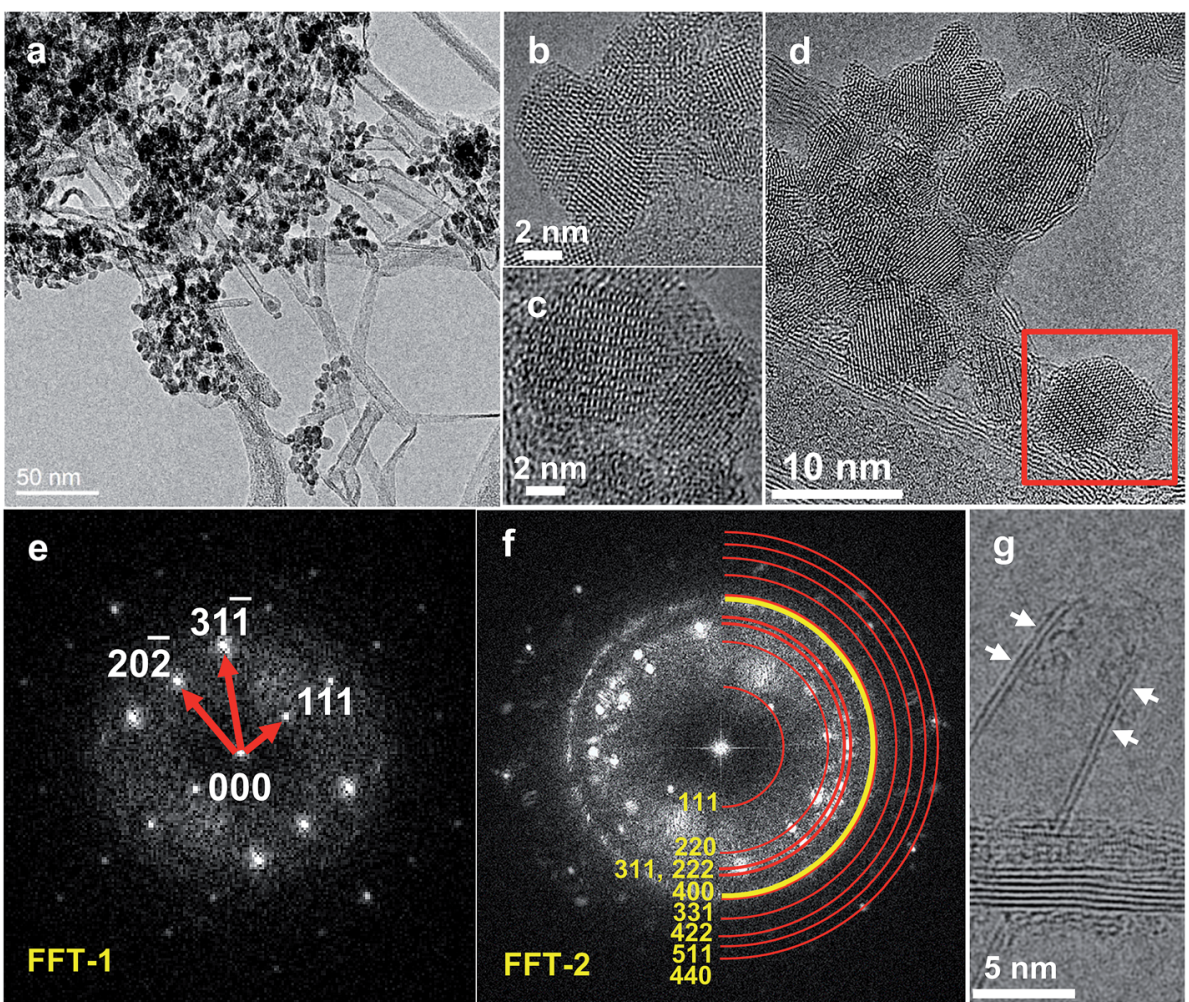

Fig. 2 Structure of $\gamma-\mathrm{Fe}_{2} \mathrm{O}_{3} / C N T$ s formed during the repeated OER sweeps of CEIN/CNT. (a) Low- and (b)-(d) high-magnification TEM images of the $\gamma-\mathrm{Fe}_{2} \mathrm{O}_{3}$ nanoparticles supported on the CNTs; (e) and (f) Fourier transform patterns calculated from the framed and the whole area of the image (d), respectively. The FFT-1 pattern can be well indexed with cubic maghemite $\left(\gamma-\mathrm{Fe}_{2} \mathrm{O}_{3}\right)$ along the [-12-1] zone axis. FFT-2 and simulated ring patterns (red rings) show the maghemite crystalline phase of the nanoparticles. The yellow ring is for the graphite 100 reflection; (g) HRTEM image of an open-ended CNT (arrows demonstrate the CNT).

repeated OER sweeps (see details of Raman data in the ESI $\dagger$ ). The increase in $I_{\mathrm{D}} / I_{\mathrm{G}}$ is attributed to the presence of oxygencontaining groups on the CNT surface formed during the electrochemical treatment. However, the change in polarization curves cannot be attributed to the CNTs, since repeated potential cycling of pristine CNTs in the alkaline solution in the similar potential range has not shown any significant change in the OER polarization curves compared to the pristine CNTs. ${ }^{23}$ After the OER current of CEIN/CNT is stabilized and $\gamma-\mathrm{Fe}_{2} \mathrm{O}_{3} /$ CNTs is formed, Raman spectra at the low-frequency region (Fig. 3a) display the appearance of new features mainly at around 350 and $700 \mathrm{~cm}^{-1}$ which are attributed to the Raman active modes of maghemite, $\mathrm{E}_{\mathrm{g}}$ and $\mathrm{A}_{1 \mathrm{~g}}$, respectively. ${ }^{36,37}$

Fig. $3 \mathrm{~b}$ and $\mathrm{S} 7 \dagger$ demonstrate spectra taken by X-ray photoelectron spectroscopy (XPS) of the CEIN/CNT sample before and after 3 OER sweeps (anodic potential sweeps between 1.0 and $1.65 \mathrm{~V}$ ) at a scan rate of $5 \mathrm{mV} \mathrm{s}^{-1}$ and a rotation of $1600 \mathrm{rpm}$ in $1 \mathrm{M} \mathrm{NaOH}$. In addition, the corresponding elemental compositions are represented in Table S1. $\dagger$ In Fig. 3, there are two main peaks at binding energies of $\sim 707$ and $\sim 720 \mathrm{eV}$ for CEIN/CNT which were ascribed to the metallic $\mathrm{Fe} 2 \mathrm{p}_{3 / 2}$ and $\mathrm{Fe} 2 \mathrm{p}_{1 / 2}$ peaks, respectively. However, after 3 OER sweeps only a small amount of pure metallic Fe in the XPS spectrum was detected and additional Fe $2 p_{3 / 2}$ and $\mathrm{Fe} 2 \mathrm{p}_{1 / 2}$ peaks were detected at 711.2 and $724.7 \mathrm{eV}$, respectively, which are similar to the values reported for maghemite $\left(\gamma-\mathrm{Fe}_{2} \mathrm{O}_{3}\right)$ nanoparticles in the literature. ${ }^{38-40}$
These results further evidence that the metallic iron and the surrounding carbon layers are oxidized during the electrochemical treatment.

Fig. $\mathrm{S} 8 \uparrow$ shows cyclic voltammetry (CV) curves of the CEIN/ CNT electrode before and after cycling the potential of the electrode between 1.0 and $1.65 \mathrm{~V}$ until the OER current is stabilized and $\gamma-\mathrm{Fe}_{2} \mathrm{O}_{3} / \mathrm{CNTs}$ are formed. In the active region of iron (between -0.45 and $0.45 \mathrm{~V}$ ) two main anodic and cathodic peaks of iron at $\sim 0.25$ (peak I) and $\sim-0.11 \mathrm{~V}$ (peak II) appear. These peaks come from reversible redox reactions of the uncovered iron particles: ${ }^{41,42}$

$$
\begin{aligned}
& \text { Peak I: } \mathrm{Fe}(\mathrm{OH})_{2} \rightarrow \mathrm{FeOOH} \\
& \text { Peak II: } \mathrm{FeOOH} \rightarrow \mathrm{Fe}(\mathrm{OH})_{2}
\end{aligned}
$$

The intensities of these peaks were weak in the initial CEIN/ CNT sample since most of the iron particles are covered by graphene layers. After the potential cycling, the faradaic currents increase dramatically in the active region, attributed to the activation of iron oxide nanoparticles as a consequence of the removal of the carbon cages surrounding Fe nanoparticles in the CEINs.

Nieuwoudt et al. investigated the composition of the passive film formed on iron in $0.05 \mathrm{M} \mathrm{NaOH}$ by in situ Raman microspectroscopy. ${ }^{42}$ They indicated that after potential cycling in 

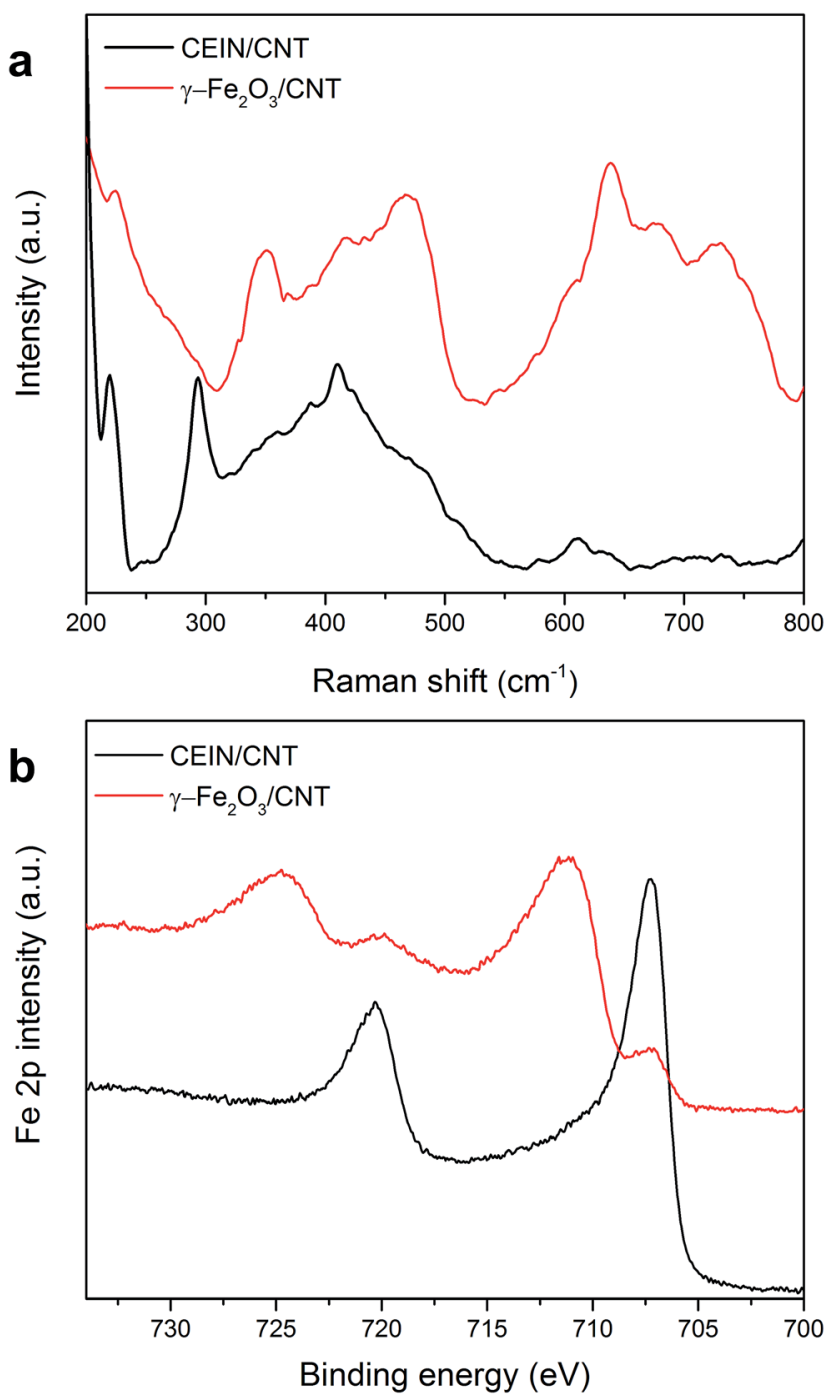

Fig. 3 XPS and Raman characterization. (a) Raman spectra and (b) Fe $2 p$ XPS region of CEIN/CNT (black lines) and its transformed structure $\left(\gamma-\mathrm{Fe}_{2} \mathrm{O}_{3} / \mathrm{CNTS}\right.$, red lines) after OER electrochemical measurements (red lines).

$\mathrm{NaOH}$ solution $\alpha$-FeOOH, $\gamma$-FeOOH, $\delta$-FeOOH and $\gamma-\mathrm{Fe}_{2} \mathrm{O}_{3}$ are the possible forms of the passive layers on iron. However, they have shown that the main passive layer is $\gamma-\mathrm{Fe}_{2} \mathrm{O}_{3}$ if the voltage applied to iron is close to the OER potential range. These results are in agreement with the above presented results based on HRTEM, XPS and Raman analysis, showing that after voltammetric cycling of the carbon enclosed Fe nanoparticles between 1.0-1.65 V (the potential range close to the OER scan), the Fe particles in the CEIN/CNT sample are converted mainly to $\gamma-\mathrm{Fe}_{2} \mathrm{O}_{3}$.

\subsection{Oxygen evolution activity and discussion}

As explained before and shown in Fig. S9, $\uparrow \gamma-\mathrm{Fe}_{2} \mathrm{O}_{3} / \mathrm{CNTs}$ were obtained by sweeping or cycling the potential applied to the CEIN/CNT electrode continuously between 1 and $1.65 \mathrm{~V} v s$. RHE in $\mathrm{NaOH}$ until stabilized current for the OER was established. Fig. 4a shows typical rotating disk electrode (RDE) polarization curves of the OER on the stabilized $\gamma-\mathrm{Fe}_{2} \mathrm{O}_{3} / \mathrm{CNT}$ sample compared to single-walled carbon nanotubes (SWNTs), Pt/C, and $\mathrm{IrO}_{2}$ electrodes in $0.1 \mathrm{M} \mathrm{NaOH}$. The $\gamma-\mathrm{Fe}_{2} \mathrm{O}_{3} / \mathrm{CNT}$ material exhibited a high OER catalytic activity with an onset overpotential of merely $300 \mathrm{mV}$ (the thermodynamic oxygen evolution potential is $1.23 \mathrm{~V}$ vs. RHE) in $0.1 \mathrm{M} \mathrm{NaOH}$. All the measured catalysts were deposited on a glassy carbon electrode with a similar loading of $\sim 0.2 \mathrm{mg} \mathrm{cm}^{-2}$.

The current observed in the high applied potential range can result from a four electron transfer reaction resulting in oxygen evolution or from an unwanted two electron transfer reaction resulting in hydrogen peroxide formation. On the other hand, oxidation of the CNT support as a side reaction can also take place. To investigate the efficiency of the OER, the oxygen evolution at $\gamma-\mathrm{Fe}_{2} \mathrm{O}_{3} / \mathrm{CNT}$ s is also monitored with a rotating ring disk electrode (RRDE) in nitrogen-saturated $0.1 \mathrm{M} \mathrm{NaOH} .^{5,8,23}$ In RRDE measurements, the evolved oxygen at the disk was then reduced at the surrounding Pt ring electrode that was held at $0.4 \mathrm{~V}$. Fig. $4 \mathrm{~b}$ shows that at the potentials above the onset of the OER $(1.53 \mathrm{~V})$ for the disk electrode, the current attributed to the oxygen reduction reaction (ORR) at the $\mathrm{Pt}$ ring electrode is detected, indicating the evolution and the following reduction of oxygen at the disc and ring electrodes, respectively. The RRDE measurements can be also used for quickly screening the approximate Faradaic efficiency of $\mathrm{O}_{2}$ production $(\varepsilon)$, by the equation of $j_{\text {ORR }} / j_{\text {OER }} \times N$, where $j_{\text {ORR }}$ and $j_{\text {OER }}$ are current densities measured on the Pt ring and on the glassy carbon disc, respectively, and $N$ is the collection efficiency of the RRDE. ${ }^{\mathbf{8 , 1 3 , 2 3}}$ In general, $\varepsilon>90 \%$ for the OER at different measurements on the $\gamma-\mathrm{Fe}_{2} \mathrm{O}_{3} / \mathrm{CNT}$ catalyst was obtained in $0.1 \mathrm{M} \mathrm{NaOH}$. It should be noted that small errors in the ring current and collection efficiency can lead to relatively large errors in $\varepsilon$, but RRDE measurements are still useful for rapidly screening the approximate faradaic efficiency. ${ }^{8}$ By changing the ring electrode potential to $1.4 \mathrm{~V}$, the generation of $\mathrm{H}_{2} \mathrm{O}_{2}$ was monitored. Through this measurement, no detectable current from $\mathrm{H}_{2} \mathrm{O}_{2}$ oxidation at the Pt ring was observed, indicating that $\mathrm{H}_{2} \mathrm{O}_{2}$ is not produced on the disc electrode (Fig. S10 $\dagger$ ). These results confirmed that the water oxidation at the $\gamma-\mathrm{Fe}_{2} \mathrm{O}_{3} / \mathrm{CNT}$ electrode proceeds via a 4-electron transfer process to generate dioxygen (the OER pathway: $4 \mathrm{OH}^{-} \rightarrow \mathrm{O}_{2}+2 \mathrm{H}_{2} \mathrm{O}+4 \mathrm{e}^{-}$).

Fig. 4c demonstrates OER polarization curves with $i R$ compensation obtained with $\gamma-\mathrm{Fe}_{2} \mathrm{O}_{3} /$ CNTs in 0.1 and $1 \mathrm{M}$ $\mathrm{NaOH}$. The potentials required to obtain a current density of 10 $\mathrm{mA} \mathrm{cm}{ }^{-2}$ are measured to be 1.61 and $1.57 \mathrm{~V}$ in 0.1 and $1 \mathrm{M}$ $\mathrm{NaOH}$, respectively. These values are comparable to the recently reported highly active transition-/noble-metal and non-metal catalysts for the OER (see Table S2 $\dagger$ ). Fig. 1d shows the Tafel plots of $\gamma-\mathrm{Fe}_{2} \mathrm{O}_{3} / \mathrm{CNT}$ in the OER derived from Fig. 1c. $\gamma-\mathrm{Fe}_{2} \mathrm{O}_{3} /$ CNTs resulted in Tafel slopes of 50 and $45 \mathrm{mV}$ per decade in 0.1 and $1 \mathrm{M} \mathrm{NaOH}$, respectively, which are smaller than the values recently reported for carbon and/or metal hybrids. ${ }^{13,19,43,44}$ The Tafel plots with good linearity and small slopes imply that $\gamma-\mathrm{Fe}_{2} \mathrm{O}_{3} / \mathrm{CNTs}$ are an efficient catalyst for the OER with a high electrical conductivity for fast electron transfer. Hence, $\gamma-\mathrm{Fe}_{2} \mathrm{O}_{3} /$ CNTs are introduced as a novel non-precious catalyst for the OER with an activity that rivals the most active reported electrocatalysts for the OER (Table $\mathrm{S} 2 \dagger$ ). 

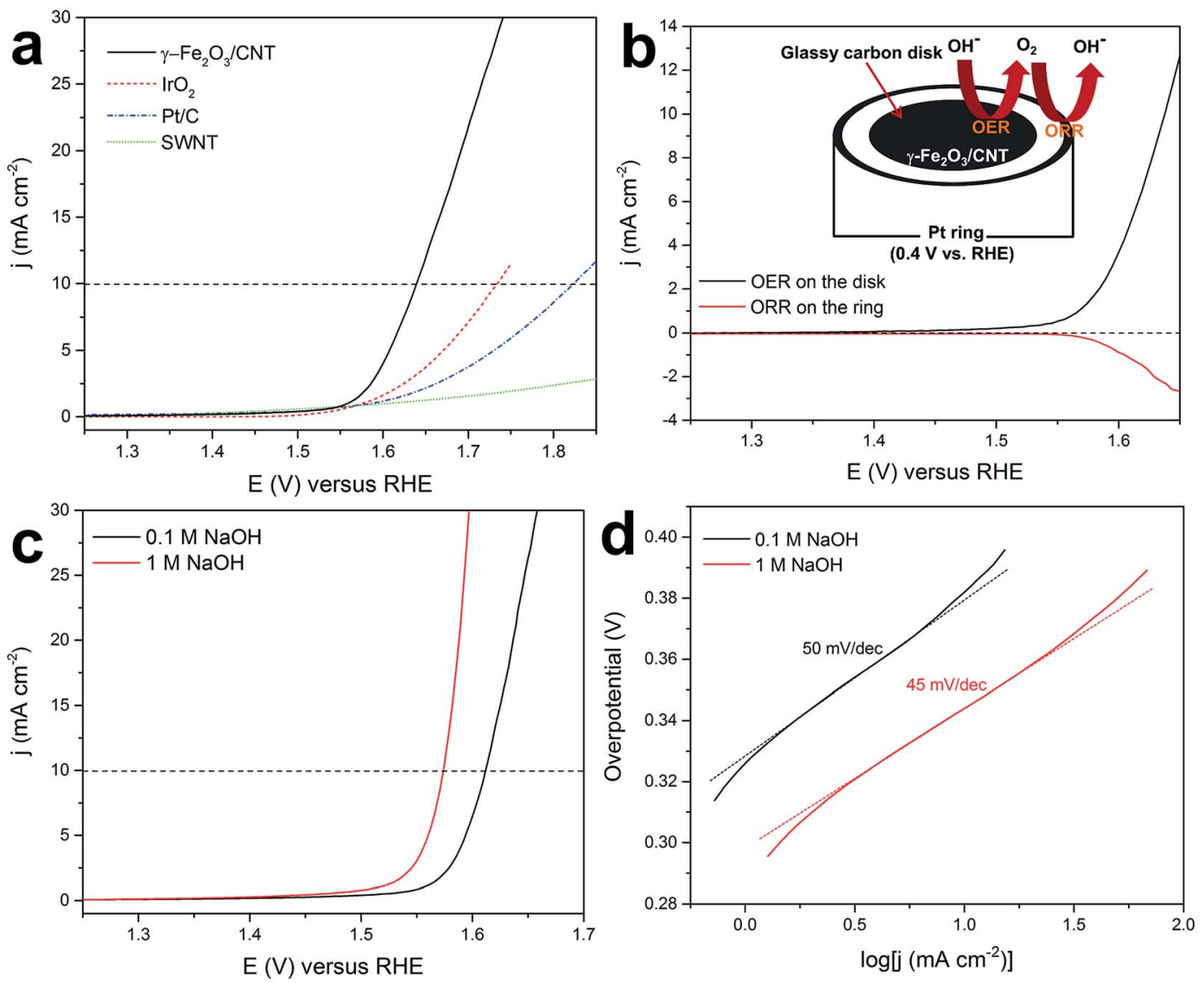

Fig. 4 Electrochemical characterization of $\gamma-\mathrm{Fe}_{2} \mathrm{O}_{3} / \mathrm{CNTs}$ for the OER. (a) The RDE polarization curves obtained with $\mathrm{Fe} 2 \mathrm{O}_{3} / \mathrm{CNTs}$, Ir $\mathrm{O}_{2}$, Pt/C (20 wt\%), and SWNTs in $0.1 \mathrm{M} \mathrm{NaOH}$ solution. (b) Detection of $\mathrm{O}_{2}$ evolution from the $\gamma$ - $\mathrm{Fe}_{2} \mathrm{O}_{3} / \mathrm{CNT}$ catalyst in $0.1 \mathrm{M} \mathrm{NaOH}$ solution using RRDE measurements (the inset shows the schematic of RRDE detection for the ORR on the Pt ring caused by the OER on the disk). The oxygen evolved during the anodic potential sweep on the disk is subsequently reduced at the Pt ring held at a constant potential of $0.4 \mathrm{~V}$. (c) RDE voltammograms with $i R$ compensation and (d) corresponding Tafel slopes obtained with the $\mathrm{Fe}_{2} \mathrm{O}_{3} / \mathrm{CNT}$ electrode in 0.1 (black lines) and $1 \mathrm{M}$ (red lines) $\mathrm{NaOH}$ solutions. The polarization curves were measured at a scan rate of $5 \mathrm{mV} \mathrm{s}^{-1}$ and a rotation of $1600 \mathrm{rpm}$.

The electrochemically active surface area (ECSA) of the $\gamma-\mathrm{Fe}_{2} \mathrm{O}_{3} / \mathrm{CNT}$ catalyst was estimated from the electrochemical double-layer capacitance of the catalytic surface ${ }^{8,23}$ (see Calculation details in the ESI $†$ ). The double-layer capacitance was calculated from the non-faradaic capacitive current associated with the charging current measured from the cyclic voltammograms (CVs) at different scan rates (Fig. S11†). ${ }^{8,23,45}$ The ECSA and roughness factor (RF) of the $\gamma-\mathrm{Fe}_{2} \mathrm{O}_{3} / \mathrm{CNT}$ catalyst were estimated to be $35 \mathrm{~cm}^{2}$ and 280 , respectively, which are significantly higher than the corresponding values of the previously reported highly active catalysts for the OER, ${ }^{8,23}$ indicating a large active surface area contributing to the high activity of the investigated electrocatalyst.

Previous studies have resulted in poor OER catalytic activity for hematite $\left(\alpha-\mathrm{Fe}_{2} \mathrm{O}_{3}\right),{ }^{12} \mathrm{Fe}$ films ${ }^{10}$ and modified CNTs with $\mathrm{Fe}_{2} \mathrm{O}_{3}$ (probably $\alpha-\mathrm{Fe}_{2} \mathrm{O}_{3}$ ) nanoparticles. ${ }^{23}$ Recently, the synthesis of maghemite nanorods anchored on 3D nitrogen doped carbon nanotubes showed an improvement in the activity of iron oxide for OER electrocatalytic activity, although the activity was still significantly lower than the highly reported active electrocatalysts for the OER. ${ }^{46}$ In contrast, we observed a high OER catalytic activity for $\gamma-\mathrm{Fe}_{2} \mathrm{O}_{3}$ nanoparticles decorated on the CNTs. The high OER activity in our catalyst is attributed to the maghemite $\left(\gamma-\mathrm{Fe}_{2} \mathrm{O}_{3}\right)$ nanoparticles compared to hematite $\left(\alpha-\mathrm{Fe}_{2} \mathrm{O}_{3}\right)$, and very high ECSA of the $\gamma-\mathrm{Fe}_{2} \mathrm{O}_{3} / \mathrm{CNT}$ catalyst synthesized in this work as well as high conductivity of the catalyst brought by the CNT support.

For the $\gamma-\mathrm{Fe}_{2} \mathrm{O}_{3} / \mathrm{CNT}$ electrode, stability tests were performed in $0.1 \mathrm{M} \mathrm{NaOH}$ by cycling the potential between 1 and $1.75 \mathrm{~V}$ at a scan rate of $50 \mathrm{mV} \mathrm{s}^{-1}$ (Fig. 5a) and measuring the time dependence of the current density at a static potential of $1.64 \mathrm{~V}$ where the current density is $\sim 10 \mathrm{~mA} \mathrm{~cm}^{-2}$ (Fig. $5 \mathrm{~b}$ ). The upper limit for cycling stability measurements $(1.75 \mathrm{~V})$ corresponds roughly to a current density of $\sim 30 \mathrm{~mA} \mathrm{~cm}{ }^{-2}$. The OER polarization curves of $\gamma-\mathrm{Fe}_{2} \mathrm{O}_{3} / \mathrm{CNTs}$ before and after 100 potential cycles (Fig. 5a) revealed no observable degradation in the OER activity and, as shown above (see TEM images in Fig. 2 which were taken after the stability measurements), the $\gamma-\mathrm{Fe}_{2} \mathrm{O}_{3}$ nanoparticles are still well dispersed on the CNT support. Likewise, the chronoamperometric curve (Fig. 5b) showed that the current density remains stable, apart from a small fluctuation in the current, during the course of the water electrolysis. This fluctuation is attributed to oxygen gas bubbles formed by molecular oxygen evolved in the reaction. These hydrophobic 

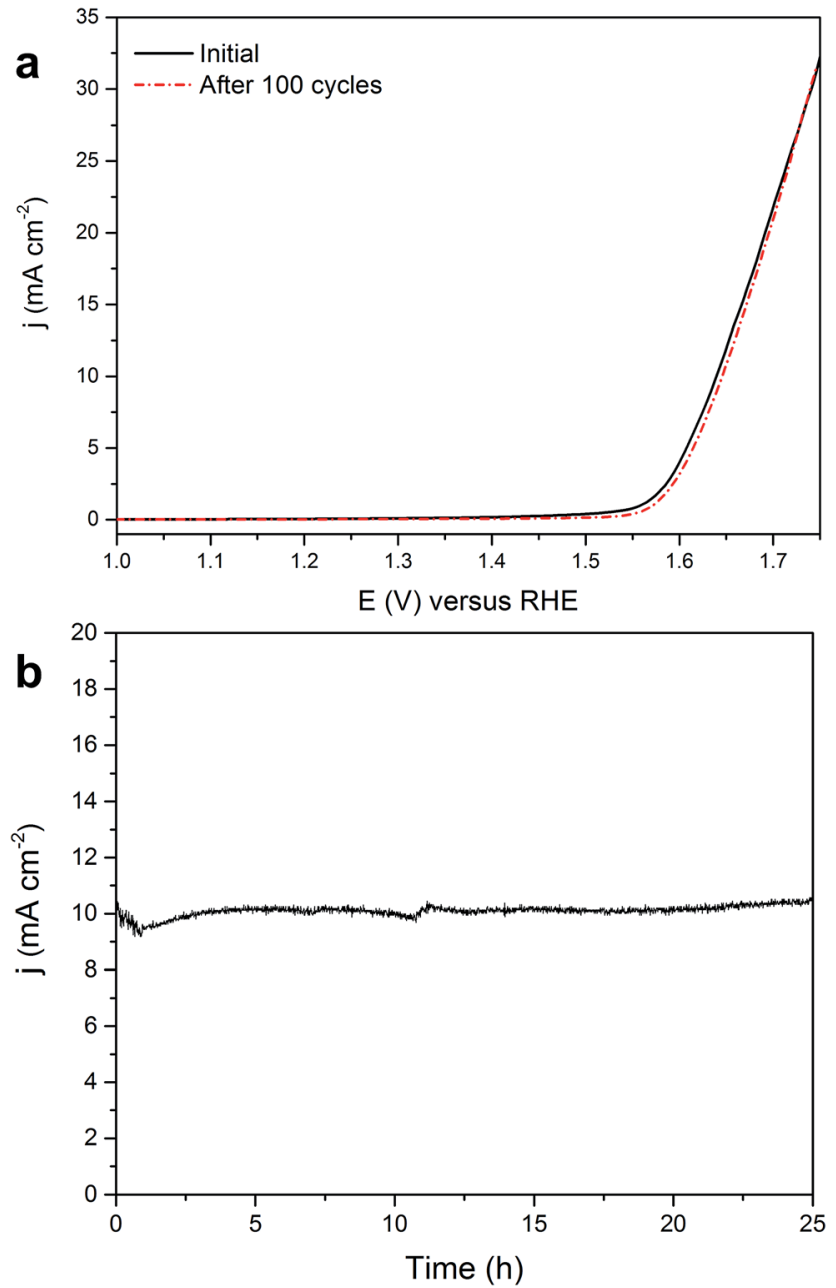

Fig. 5 Stability test of the $\gamma-\mathrm{Fe}_{2} \mathrm{O}_{3} / \mathrm{CNT}$ catalyst for oxygen evolution. (a) The polarization curves of $\gamma-\mathrm{Fe}_{2} \mathrm{O}_{3} / \mathrm{CNTs}$ before the cycling durability test (black solid line) and after cycling 100 cycles (red dash dot line) between the potentials of 1 and $1.75 \mathrm{~V}$ vs. RHE at a scan rate of $50 \mathrm{mV} \mathrm{s}^{-1}$, and (b) time dependence of the current density obtained at a static potential of $\sim 1.64 \mathrm{~V}$ in $0.1 \mathrm{M} \mathrm{NaOH}$.

gas bubbles are prone to attach on the electrocatalyst surface resulting in temporary blocking of the active surface sites until they grow large enough and are detached form the surface, resulting in the observed fluctuation in the current. These results indicate that $\gamma-\mathrm{Fe}_{2} \mathrm{O}_{3} / \mathrm{CNTs}$ are stable and active electrocatalysts for the OER in alkaline media.

Electrochemical purification is an efficient way to purify CNTs from iron impurities. ${ }^{47}$ To observe the contribution of CNTs in the OER activity of the CEIN/CNT sample, we electrochemically purified the CEIN/CNT sample from iron impurities through 5 potential cycles between 1 and $1.6 \mathrm{~V} v s$. RHE in $0.5 \mathrm{M}$ $\mathrm{H}_{2} \mathrm{SO}_{4}$ at a scan rate of $50 \mathrm{mV} \mathrm{s}{ }^{-1}$. TEM images from the CEIN/ CNT material after purification (Fig. S12†) indicate the removal of iron impurities from the surface of the CNTs. Furthermore, the HRTEM images from the purified sample demonstrate that this electrochemical purification opens the caps of the CNTs while the structure of the sidewalls of the CNTs is preserved. After purification, CNTs confirmed negligible OER catalytic activity in $0.1 \mathrm{M} \mathrm{NaOH}$ alkaline solution, compared to the $\gamma$ $\mathrm{Fe}_{2} \mathrm{O}_{3} / \mathrm{CNT}$ catalyst (Fig. S13 $\dagger$ ). Therefore, the high catalytic activity in $\gamma-\mathrm{Fe}_{2} \mathrm{O}_{3} /$ CNTs is associated solely to the $\gamma-\mathrm{Fe}_{2} \mathrm{O}_{3}$ nanoparticles decorated on the CNT support.

\section{Conclusions}

In summary, the CEIN/CNT material is synthesized by a fast and low cost floating catalyst CVD method in a one-step synthesis with a similar growth process to that of the CNTs. By cycling or sweeping the potential applied to the CEIN/CNT electrode, carbon cages in CEINs and the caps of the CNTs are selectively stripped off from the electrode. Subsequently, $\gamma-\mathrm{Fe}_{2} \mathrm{O}_{3}$ nanoparticles decorated on the CNTs $\left(\gamma-\mathrm{Fe}_{2} \mathrm{O}_{3} / \mathrm{CNTs}\right)$ are formed with high activity and durability for catalyzing the OER, comparable to the most active OER electrocatalysts. This study shows for the first time that iron oxide can be used directly as a highly active electrocatalyst material for the OER. Our findings open the door to new OER catalyst materials synthesized by modifying the growth process of CNTs as one of the most interesting materials in science and industry. The unique electrical and magnetic properties of maghemite nanoparticles can also expand the potential applications of this material.

\section{Acknowledgements}

This work is supported by Aalto University (MOPPI project in AEF program) and Academy of Finland (the DEMEC and SUPER projects). This work made use of the Aalto University Nanomicroscopy Center (Aalto-NMC) premises.

\section{References}

1 M. G. Walter, E. L. Warren, J. R. McKone, S. W. Boettcher, Q. Mi, E. A. Santori and N. S. Lewis, Chem. Rev., 2010, 110, 6446-6473.

2 T. R. Cook, D. K. Dogutan, S. Y. Reece, Y. Surendranath, T. S. Teets and D. G. Nocera, Chem. Rev., 2010, 110, 64746502.

3 N. S. Lewis and D. G. Nocera, Proc. Natl. Acad. Sci. U. S. A., 2006, 103, 15729-15735.

4 M. Gong and H. Dai, Nano Res., 2015, 8, 23-39.

5 J. Suntivich, K. J. May, H. A. Gasteiger, J. B. Goodenough and Y. Shao-Horn, Science, 2011, 334, 1383-1385.

6 Y. Lee, J. Suntivich, K. J. May, E. E. Perry and Y. Shao-Horn, J. Phys. Chem. Lett., 2012, 3, 399-404.

7 T. Reier, M. Oezaslan and P. Strasser, ACS Catal., 2012, 2, 1765-1772.

8 C. C. L. McCrory, S. Jung, J. C. Peters and T. F. Jaramillo, J. Am. Chem. Soc., 2013, 135, 16977-16987.

9 L. Trotochaud, J. K. Ranney, K. N. Williams and S. W. Boettcher, J. Am. Chem. Soc., 2012, 134, 17253-17261.

10 M. W. Louie and A. T. Bell, J. Am. Chem. Soc., 2013, 135, 12329-12337.

11 M. Ledendecker, G. Clavel, M. Antonietti and M. Shalom, Adv. Funct. Mater., 2015, 25, 393-399. 
12 R. D. L. Smith, M. S. Prévot, R. D. Fagan, Z. Zhang, P. A. Sedach, M. K. J. Siu, S. Trudel and C. P. Berlinguette, Science, 2013, 340, 60-63.

13 T. Y. Ma, S. Dai, M. Jaroniec and S. Z. Qiao, J. Am. Chem. Soc., 2014, 136, 13925-13931.

14 W. Zhou, X.-J. Wu, X. Cao, X. Huang, C. Tan, J. Tian, H. Liu, J. Wang and H. Zhang, Energy Environ. Sci., 2013, 6, 29212924.

15 Z. Zhao, H. Wu, H. He, X. Xu and Y. Jin, Adv. Funct. Mater., 2014, 24, 4698-4705.

16 Y. Yang, H. Fei, G. Ruan, C. Xiang and J. M. Tour, ACS Nano, 2014, 8, 9518-9523.

17 X. Lu and C. Zhao, J. Mater. Chem. A, 2013, 1, 12053-12059.

18 K. Mette, A. Bergmann, J.-P. Tessonnier, M. Hävecker, L. Yao, T. Ressler, R. Schlögl, P. Strasser and M. Behrens, ChemCatChem, 2012, 4, 851-862.

19 S. Dou, L. Tao, J. Huo, S. Wang and L. Dai, Energy Environ. Sci., 2016, DOI: 10.1039/c6ee00054a.

20 Y. Liang, Y. Li, H. Wang and H. Dai, J. Am. Chem. Soc., 2013, 135, 2013-2036.

21 G. G. Wildgoose, C. E. Banks and R. G. Compton, Small, 2006, 2, 182-193.

22 W. Zhang, P. Sherrell, A. I. Minett, J. M. Razal and J. Chen, Energy Environ. Sci., 2010, 3, 1286-1293.

23 X. Lu, W.-L. Yim, B. H. R. Suryanto and C. Zhao, J. Am. Chem. Soc., 2015, 137, 2901-2907.

24 Y. Cheng, C. Xu, L. Jia, J. D. Gale, L. Zhang, C. Liu, P. K. Shen and S. P. Jiang, Appl. Catal., B, 2015, 163, 96-104.

25 M. Gong, Y. Li, H. Wang, Y. Liang, J. Z. Wu, J. Zhou, J. Wang, T. Regier, F. Wei and H. Dai, J. Am. Chem. Soc., 2013, 135, 8452-8455.

26 M. Tavakkoli, T. Kallio, O. Reynaud, A. G. Nasibulin, C. Johans, J. Sainio, H. Jiang, E. I. Kauppinen and K. Laasonen, Angew. Chem., Int. Ed., 2015, 54, 4535-4538.

27 X. Zou, X. Huang, A. Goswami, R. Silva, B. R. Sathe, E. Mikmeková and T. Asefa, Angew. Chem., 2014, 126, 4461-4465.

28 J. Deng, P. Ren, D. Deng and X. Bao, Angew. Chem., Int. Ed., 2015, 54, 2100-2104.

29 J. Wang, G. Wang, S. Miao, J. Li and X. Bao, Faraday Discuss., 2014, 176, 135-151.
30 Y. Hu, J. O. Jensen, W. Zhang, L. N. Cleemann, W. Xing, N. J. Bjerrum and Q. Li, Angew. Chem., Int. Ed., 2014, 53, 3675-3679.

31 O. Reynaud, A. G. Nasibulin, A. S. Anisimov, I. V. Anoshkin, H. Jiang and E. I. Kauppinen, Chem. Eng. J., 2014, 255, 134140.

32 H. Yoshida, S. Takeda, T. Uchiyama, H. Kohno and Y. Homma, Nano Lett., 2008, 8, 2082-2086.

33 M. Kumar, Carbon Nanotube Synthesis and Growth Mechanism, InTech, 2011.

34 C. T. Wirth, S. Hofmann and J. Robertson, Diamond Relat. Mater., 2009, 18, 940-945.

35 P. M. Ajayan, T. W. Ebbesen, T. Ichihashi, S. Iijima, K. Tanigaki and H. Hiura, Nature, 1993, 362, 522-525.

36 A. M. Jubb and H. C. Allen, ACS Appl. Mater. Interfaces, 2010, 2, 2804-2812.

37 D. L. A. de Faria, S. Venâncio Silva and M. T. de Oliveira, J. Raman Spectrosc., 1997, 28, 873-878.

38 T. Hyeon, S. S. Lee, J. Park, Y. Chung and H. B. Na, J. Am. Chem. Soc., 2001, 123, 12798-12801.

39 H. Park, P. Ayala, M. A. Deshusses, A. Mulchandani, H. Choi and N. V. Myung, Chem. Eng. J., 2008, 139, 208-212.

40 Z. Sun, Z. Liu, Y. Wang, B. Han, J. Du and J. Zhang, J. Mater. Chem., 2005, 15, 4497-4501.

41 A. H. L. Goff, J. Flis, N. Boucherit, S. Joiret and J. Wilinski, J. Electrochem. Soc., 1990, 137, 2684-2690.

42 M. K. Nieuwoudt, J. D. Comins and I. Cukrowski, J. Raman Spectrosc., 2011, 42, 1353-1365.

43 T. Y. Ma, S. Dai, M. Jaroniec and S. Z. Qiao, Angew. Chem., Int. Ed., 2014, 53, 7281-7285.

44 S. Mao, Z. Wen, T. Huang, Y. Hou and J. Chen, Energy Environ. Sci., 2014, 7, 609-616.

45 J. D. Benck, Z. Chen, L. Y. Kuritzky, A. J. Forman and T. F. Jaramillo, ACS Catal., 2012, 2, 1916-1923.

46 T. Sharifi, W. L. Kwong, H.-M. Berends, C. Larsen, J. Messinger and T. Wågberg, Int. J. Hydrogen Energy, 2016, 41, 69-78.

47 A. Heras, A. Colina, J. López-Palacios, P. Ayala, J. Sainio, V. Ruiz and E. I. Kauppinen, Electrochem. Commun., 2009, 11, 1535-1538. 